\title{
Coccidioidomycosis: Medical and Spatio-Temporal Perspectives
}

\author{
Nikias Sarafoglou ${ }^{1}$, Rafael Laniado-Laborin ${ }^{2}$, Menas Kafatos ${ }^{3}$ \\ ${ }^{1}$ George Mason University, Arlington, Virginia, USA \\ ${ }^{2}$ Universidad Autonoma de Baja California, Tijuana, Mexico \\ ${ }^{3}$ Chapman University, Orange, California, USA \\ Correspondence: Nikias Sarafoglou, George Mason University, Arlington, Virginia, USA.
}

Received: July 22, 2019

doi:10.11114/ijsss.v7i6.4539
Accepted: August 29, $2019 \quad$ Available online: September 24, 2019

URL: https://doi.org/10.11114/ijsss.v7i6.4539

\begin{abstract}
Coccidioidomycosis (CM) is a disease of major public health importance due to the challenges in its diagnosis and treatment. To understand CM requires the attributes of a multidisciplinary network analysis to appreciate the complexity of the medical, the environmental and the social issues involved: public health, public policy, geology, atmospheric science, agronomy, social sciences and finally humanities, all which provide insight into this population transformation.

In section 1 of this paper, we describe the CM-epidemiology, the clinical features, the diagnosis and finally the treatment.

In section 2, we highlight the most important contributions and controversies in the history of the CM-research by using scientometric or bibliometric evaluations of research that are based on Garfield's work (Garfield.library.upenn.edu) on the propagation of scientific thinking.
\end{abstract}

Keywords: Coccidioidomycosis, Valley Fever, epidemiology, fungal infection, disseminated, azoles, bibliometrics, spatio-temporal analysis

\section{Coccidioidomycosis: A Medical Perspective}

\subsection{Introduction}

The genus Coccidioides consists of two species: C. immitis and C. posadasii.

Initially it was believed that $C$. immitis was a species that existed only in California, while $C$. posadasii was the predominant species everywhere else. However, now it has been proven that there is considerable overlap in the geographical distribution of both species. Nonetheless, they are identical in their clinical presentation and management (Twarog, et al., 2015).

Coccidioides spp. was initially thought to be a protozoan that caused severe disease; the original name for this pathogenic fungus was Coccidioides immitis (from the Latin Coccidia protozoan and immitis "not mild"). Later on, was classified as a dimorphic fungus from the family Onygenaceae.

The life cycle of this fungus includes a pathogenic phase, characterized by a structure called spherule that originates from an inhaled (rarely inoculated trans dermally) arthroconidia, a saprophyte structure that develops in the environment. A mycelium form that matures into alternating arthroconidia characterizes the environmental phase. Once the arthroconidia are inhaled into the host lungs, it will transform into a spherule that as it matures develops endospores completing the life cycle. The pressure generated by the increasing number of endospores eventually ruptures the wall of the spherule, and the endospores spread to neighboring tissues, maturing, in turn, to become spherules with the subsequent progressive repetition of the cycle. The majority of ascomycete fungi are strictly saprotrophic, but Coccidioides spp. has developed the ability to infect mammals including humans.

Both Coccidioides species grow in arid to semiarid alkaline soils in the Western United States, Northern Mexico, isolated regions of Central and South America. Most isolates of Coccidiodes spp. have been recovered 10-30 cm. beneath the soil surface (Fisher, et al., 2007).

There is a hypothesis that Coccidioides spp. responds to moisture in the soil. After the seasonal rains the fungus grows as mycelium and when the soil dries out or nutrients become limiting, the fungus reproduces asexually by 
disarticulating the hyphae into arthroconidia. These are easily aerosolized when wind currents or human activities disturb the soil (Hector, et al., 2011; Tamerius, 2011). It has been reported in Arizona that low precipitation seasons correlate with a higher incidence of primary CM.

\subsection{Epidemiology}

The incidence of reported CM in the United States in the past twenty years has increased greatly. It is a disease of major public health importance due to the challenges in its diagnosis and treatment (McCotter, et al., 2019).

The hyperendemic regions in the United States are the Central Valley of California and Southern Arizona; most cases (>95\%) are reported in those two states. In 2016, California reported a record number of cases (Cooksey, et al., 2017). About $1-2 \%$ of the cases in the United States are reported in Nevada, New Mexico, and Utah.

The increase in the number of cases is multifactorial. For example in Arizona, there has been a $75 \%$ increase in the population from 1990 to 2010 in part due to migration, with people likely to be immune-naïve to CM; as a result of this expansion in the population, there has been also an increase in the development of suburban areas of desert type in the Phoenix and Tucson metropolitan areas, with the consequent removal of the soil and increase in the exposure of dust in the air (McCotter, et al., 2019).

$\mathrm{CM}$ is the most prevalent of the systemic mycosis in Mexico and infection is as prevalent as in the endemic regions of the United States (Ajello, 1967). Baja California, Coahuila, Sonora, and Nuevo Leon have reported the highest rates of infection in Mexico. The endemic regions in Mexico, like in the United States, are characterized by a dry climate, alkaline soil, and summers with temperatures as high as $50^{\circ} \mathrm{C}$ and very low annual precipitations. All these environmental factors favor the presence of Coccidioides and its spread through air currents (Laniado-Laborin, 2006).

The prevalent species in Mexico is $C$. posadasii (Bialek, et al., 2004), although $C$. immitis has been also isolated in the northwestern states.

The clinical burden of disease in Mexico is currently unknown (Castañon-Olivares, et al., 2004). CM was a reportable disease in Mexico up to 1994, with an average then of 1,500 cases per year (Baptista-Rosas, et al., 2007).

Information about CM in Central America is scarce and autochthonous human cases have been reported in Guatemala and Honduras (Castro, et al., 1951; Perez-Guisasola et al., 1960; Garcia-Valdez, et al., 1960). Cases are reported sporadically in Honduras while in Guatemala an average of 6 cases of CM is reported annually, mostly in HIV-infected individuals. Based on the results of skins surveys with coccidioidin, more cases should be expected in the region, but lack of awareness of the disease and the absence of equipped laboratories for mycological diagnosis contribute to its sub diagnosis. The predominant species in Guatemala is $C$. posadasii, although $C$. immitis can also be isolated in the region (Engelthaler, et al., 2016).

CM incidence in South America is unknown for several reasons: it is not a reportable disease, there is little awareness of the disease and it might be misdiagnosed as tuberculosis, which is also endemic and more frequent in the region. As in other regions, CM in South America is endemic in arid and semiarid areas with alkaline soil and extreme temperatures, with cases being reported in Colombia, Venezuela, Brazil, Paraguay, Bolivia and Argentina (Laniado-Laborin, et al., 2019).

Although all those exposed can be infected, there are certain risk factors for developing severe forms of Coccidioidomycosis. African Americans, Filipinos, pregnant women, and immunosuppressed patients have a higher risk of dissemination (Odio, et al., 2017).

Certain occupational exposures such as working in construction, agricultural or archeological work has been associated with a higher risk of exposure and disease (Freedman, et al., 2018; Kollath, et al., 2019). Diabetes is an important risk factor for CM in Mexico. The country has one of the highest rates of diabetes in the world (9.4\%) and severe forms of CM have been reported in diabetics for more than 30 years (Forsbach-Sanchez, et al., 1985).

In the United States incidence of CM increases steadily with age, with subjects $>70$ years having the highest rate reported at 209 cases per 105 population while the rate for those between 1 and 4 years of age is only 7.7 per 105 population (McCotter, et al., 2019).

\subsection{Clinical Features}

About $60 \%$ of individuals exposed to CM will develop an asymptomatic and self-limited infection and would only know that they have been infected if tested with coccidioidin/spherulin or through serology assays.

The remaining $40 \%$ will develop an infection with variable clinical features. Most will develop a primary pulmonary infection, known as Valley Fever, characterized by pneumonia, pleuritic pain/pleural effusion, arthralgia, joint swelling and different types of skin rashes, including erythema nodosum. In the vast majority of patients, this acute syndrome 
will be self-limited, sometimes leaving a lung cavity as a sequela. Within the endemic regions, a significant proportion (up to a 20-30\%) of community-acquired pneumonia correspond to primary coccidioidal pneumonia (Sunenshine, et al., 2007).

In $5 \%$ of the cases, $\mathrm{CM}$ will progress to chronic fibrocavitary lung disease or will disseminate ( $<1 \%$ of infections), involving the skin, bones/joints, the central nervous system, and other organ systems. The most serious form of CM is the meningeal infection, which occurs in less than 1\% of extrapulmonary cases (Hector, et al., 2005 ; Laniado-Laborin, 2006).

In endemic regions for tuberculosis and CM, like in northern Mexico, both diseases may coexist. They share epidemiological, clinical, and radiographic and histopathology features, which may complicate the diagnosis; the diagnosis of one of them does not exclude the existence of the other (Castañeda-Godoy, et al., 2002).

\subsection{Diagnosis}

There are several methods by which CM may be diagnosed. The isolation of Coccidioides spp. in culture is the gold standard for diagnosis. The fungus can be recovered in culture from tissues, sputum and body fluids. Isolation of Cocidioides spp. from any site is diagnostic of the disease. Cocidioides spp. does not need special culture media, although the preferred media is Saboraud agar. It grows in 3-5 days, producing highly infectious arthroconidia, which represent a significant risk to laboratory personnel; all specimens from a patient with the potential diagnosis of CM should be processed under biosafety level 3 conditions.

The identification of the typical $20-80 \mu \mathrm{m}$ spherules on sputum smears or in pathologic specimens (stained with periodic acid-Schiff or Gomori methenamine silver) also is considered confirmatory of CM; tissues will usually demonstrate a chronic granulomatous inflammatory reaction, very similar of that of tuberculosis (Twarog, et al., 2015).

There are several serological tests available for the diagnosis of CM. These include tube precipitin (TP), complement fixation (CF), immunodiffusion, latex particle agglutination (LPA) and enzyme-linked immunosorbent assays (ELISA). Immunodiffusion and CF are the most specific serology methods. They are based on the identification of $\operatorname{IgM}$ and $\operatorname{IgG}$ antibodies to the fungal antigens. In the acute phase of the primary infection, almost $50 \%$ of the patients will have detectable IgM antibodies within the first week and $90 \%$ will have antibodies by the third week; these will become negative by the third month. Conversely IgG becomes detectable within 1-3 months of initial infection and persists for months or even years. The quantitative results of $\mathrm{CF}$ are useful to determine disease severity and response to treatment (Parish, et al., 2008). LPA, like TP, detects primarily IgM. A serological ELISA method based on the detection of both $\operatorname{IgM}$ and IgG show high specificity and sensitivity (98.5 and 95.5\% respectively) and is commonly used for diagnosis. An alternative strategy is to detect fungal antigens (usually in serum) through an antigen enzyme immunoassay; one example would be the detection of Coccidioides spp. galactomannan, although there are reports of cross-reactions with another mycosis (de Aguiar Cordeiro, et al., 2013).

Commercial molecular assays are available, based on real-time PCR methods; detection and genotyping of both $C$. immitis and $C$. posadasii relies on sequencing rDNA.

\subsection{Treatment}

The primary pulmonary disease frequently does not require antifungal therapy while extrapulmonary and disseminated disease will usually require prolonged treatment (Ampel, 2015). Current guidelines recommend treatment of immunosuppressed patients, those with significant comorbidities, chronic cases and patients with $\mathrm{CF}$ titers $\geq 1: 32$ (Galziani, 2016).

Some experts recommend treatment of primary pulmonary disease in African American or Filipino patients, given the more frequent severe presentation of the disease in these ethnic groups. Other situations where experts recommend treatment are patient with extensive pneumonia and prominent hilar adenopathy (Galziani, 2000).

The first effective drug for the treatment of CM was amphotericin B but due to the need of prolonged intravenous administration and significant toxicity, it has been replaced with azole drugs (itraconazole, fluconazole, voriconazole, posaconazole, and isavuconazole). Fluconazole (90\%), voriconazole (96\%) and isavuconazole (98\%) have excellent oral bioavailability while itraconazole (55\%) and posaconazole (54\%) have poor oral bioavailability (Thompson, 2019).

An exception for the use of azoles is pregnancy during the first trimester due to the teratogenicity of azoles. Amphotericin B (lipid formulation is preferred) is the drug of choice in this population (Thompson, 2019). Azoles can replace amphotericin after the first trimester to avoid prolonged intravenous therapy and toxicity (Bergovitch, 2011).

Fluconazole is the drug of choice for the treatment of meningeal disease due to its better penetration (60\%) into the cerebrospinal fluid (CSF). The dose can range from 400 to $800 \mathrm{mg}$, but doses as high as 2,000 $\mathrm{mg}$ have been used (Johnson, 2006); itraconazole and posaconazole do not penetrate into the CSF, while voriconazole penetration in CSF is 
only $50 \%$.

Duration of therapy varies according to the disease site and severity. Primary pulmonary disease, if treated, usually requires treatment for less than six months. Meningeal CM, on the other hand, requires lifelong treatment given the high relapse rates reported when therapy is discontinued (Blair, 2009).

A well-known fact that patients who recover from CM have prolonged immunity to reinfection. This would suggest an important role for a vaccine; however, despite extensive work on development, there is no effective vaccine for clinical use to date (Pappagianis, 2001).

\section{Cocidioidomycosis: A Spatio-Temporal Perspective}

Coccidioidomycosis $(\mathrm{CM})$ is a disease of major public health importance due to the challenges in its diagnosis and treatment. To understand $\mathrm{CM}$ requires the attributes of a multidisciplinary network analysis to appreciate the complexity of the medical, the environmental and the social issues involved: public health, public policy, geology, atmospheric science, agronomy, social sciences and finally humanities, all of which provide insight into this population transformation (Smith, 1940; Fiese, 1958; Hirschmann, 2007; CDC, 2001; Galgiani, 2005 \& 2008); Pappagianis and Einstein, 1978; Sprigg_et al., 2008 \& 2012 \& 2014; Sarafoglou and Kafatos, 2013; IPCC, 2007; Hospenthal, 2013; Gia, 2014; and Deresinski and Mirels, 2019).

In section 2 of this paper, we highlight the most important contributions and controversies in the history of the CM-research by using scientometric or bibliometric research evaluations that are based on Garfield's work (Garfield.library.upenn.edu) on the propagation of scientific thinking. (Garfield initiated the old "Science Citation Index", the forerunner of the modern equivalent "Web of Science" database).

The study of CM is multi-disciplinary, with scientific and humanitarian concerns. Yet, poor communication both between and within disciplines is a recognized challenge today.

There are many scientometric or bibliometric databases, e.g. Google Scholar, PubMed/Medline, CrossRef, Web of Science, etc. Our bibliometric analysis of CM-research is based on Web of Science (WoS) database for the period 1938-2017 /1/. Our sample consists of 2,188 items.

WoS has two advantages:

1. It has a long data period.

2. It has a better classification system than the other databases e.g. Google Scholar.

\subsection{The Spatio-Temporal Distribution of the CM-Research}

The first 80 publications years of CM research by record count are shown in Figure 1.

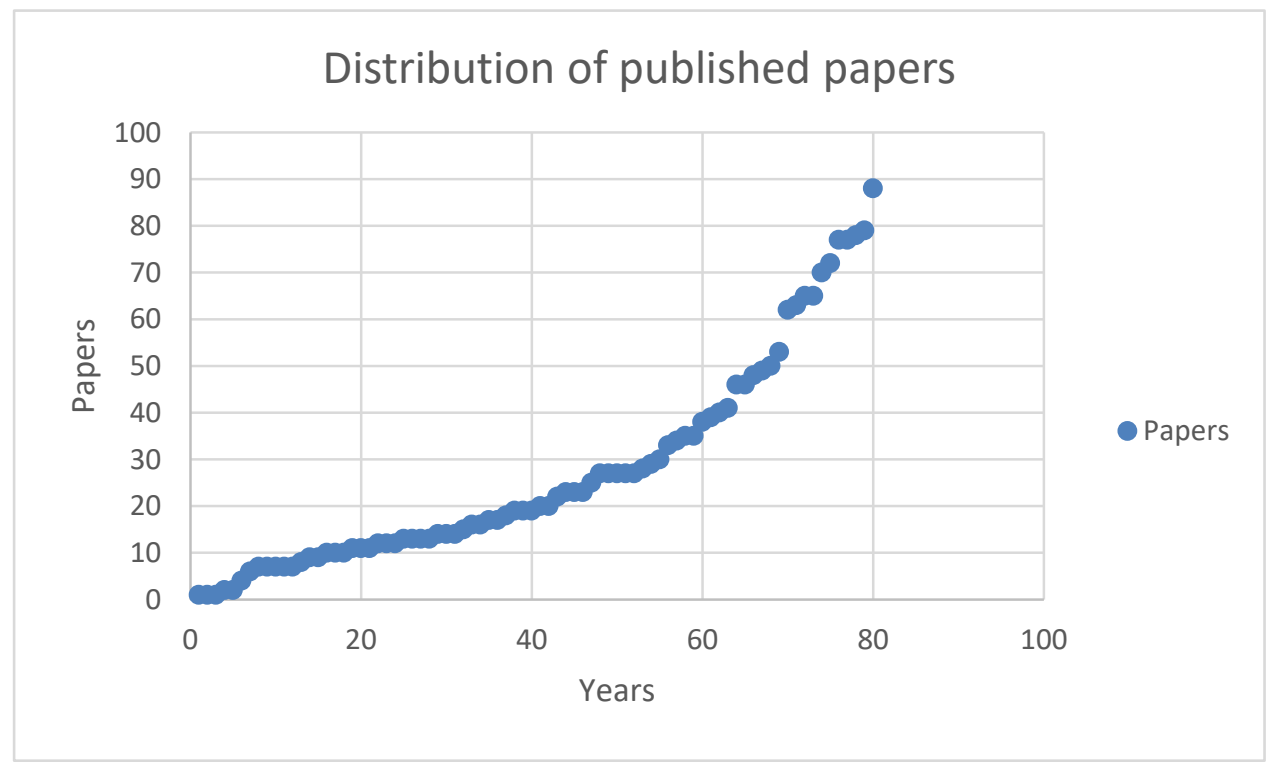

Figure 1. The first 80 publications years of $\mathrm{CM}$ research by record count 
In Figure 1, the significant increase in published works during this period can be observed. There are two important evolutions for scientific creativity during this long period 1938-2017:

1. Garfield's scientometric or bibliometric evaluations of research. Merton (1968), de Sola Price (1976) and Zuckerman (1987) extended Garfield's ideas with the "Matthew effect" and the complex problem of intellectual influence.

2. The diffusion of the Internet changed the accessibility of scientific publications. The accessibility of scientific publications is more efficient in the last years (Sarafoglou, et al., 2012).

According to the Web of Science data during the first period of CM- research, namely 1938-1978, the publication rate was low. The eponymous publications of the first period generated sufficient dynamics for new citations in the next forty years.

An interesting observation is a CM-research distribution between geographical areas and countries. One should expect North America, Central America, and South America are the most prolific areas, because of the spatial configuration of CM.

Highly endemic areas for coccidioidomycosis include California's San Joaquin Valley, and south and east along a broad swath of territory along both sides of the US-Mexico border, through Central America and deep into South America (Laniado-Laborin, 2007). Overall, even today throughout the endemic region, cocci surveillance is poor. Yet, some statistics give us an idea of the seriousness of the disease. On average, 150,000 people in the U.S. are estimated to contract valley fever annually where, between 1990 and 2008, an annual average of 161 deaths were attributed to CM. Most of these cases are unreported because initial symptoms are not severe and normal resistance prevails over time. Most documented cases come from the U.S. state of Arizona where, in 2007, approximately 3000 cases were reported (there were 6000 cases reported nation-wide), with an associated 1735 hospital visits and $\$ 86$ million in hospital charges (ADHS, 2007; ADHS, 2012).

In California, Pappagianis (1994) documented increases in CM cases from 1991 to 1993, Huang, (2012) and Sondermeyer, et al., (2013) found an average of 70 deaths each year from CM between 1997 and 2008. Medical records for Kern County, California, attribute approximately $\$ 45$ million in direct costs for hospitalization and outpatient care for CM-cases during the period 1991-1993 (CDC, 1994). And, Kern County shares much of the San Joaquin Valley.

Physicians in the US required to report a diagnosed case of CM after 1997. Also, methods of laboratory blood tests for cocci have changed over time, and the time-dependent record of surveillance for CM is poor (Sprigg, et.al., 2014).

In the next Table 1 we may note the actual research distribution of countries by record count.

Table 1. The most prolific countries in the CM-research

USA $(1,482)$
Mexico (68)
Brazil (58)
Germany (32)
Canada (27)
France (25)
Argentina (24)
England (20)
Japan (14)
Italy (14)

The USA is the dominant country in the publication of CM-research. Mexico and Brazil are the most prolific countries with Spanish or Portuguese language.

English is the modern "lingua franca" for scientific production (Sandelin and Sarafoglou, 2004). The quantity and the quality of the American Universities could be a major explanation too.

It turns out that there is a tendency for a higher publication rate for English-language countries, slightly lower for countries with small languages, and even smaller for countries with large non-English languages. This is consistent with 
the hypotheses that there is a bias in the databases from the ISI such that English-language journals tend to be overrepresented, that scholars from English-language countries write almost exclusively in English, and that scholars from other countries tend to publish less in English and more in their domestic language the larger their domestic language. This calls for caution in using these databases for international comparisons of research activity.

One of the outliers in Table 2 is Germany. Germany is not connected geographically with the CM-regions, but Germany has produced more publications than endemic countries, e.g. Argentina.

The explanation might be the educational background of the Argentinian student Alejandro Posadas. He was the first author of CM-research. He wrote, "Un nuevo caso de micosis fungoide con psorospermias" (1892). Posadas studied in Buenos Aires, and his professor Roberto Wernicke was another Argentinian with German parents. Wernicke studied at Jena University in Germany, and he became a professor in Buenos Aires after his return to Argentina.

He published an article (1892) after Posadas' publication for CM with the title "Über einen Protozoen befund bi Mykosis Fungoides". This article generated a new scientific research in Germany (Sarafoglou, et al., 2012).

There are two other prominent CM-researchers who studied or were born in Germany:

1. William Ophüls

William was born in Brooklyn, but he went to study in Germany. He returned to US after his studies at Würzburg and Göttingen, and he became a professor in California some years later.

2. Hans E. Einstein

Einstein was born in Berlin and he emigrated from Germany to the USA via Holland during Hitler's early period at age 16. He was an Albert Einstein's relative. He got a medical degree from New York Medical College. He was active in California too.

The first North American CM-article was published by Emmett Rixford and TC Gilchrist (1986). Fiese (1958) wrote that this paper "was the first extensive study of CM and the first in which the significance of the parasite, as the agent of the new and disease, was appreciated."

But Table 1 is a manifestation of international cooperation and the migration of researchers.

\subsection{The Publications}

Another interesting question is the distribution of Science Categories of the CM-research.

In the next Table 2 this distribution is depicted:

Table 2. The distribution of Science Categories and Source Titles of the CM-research

Infectious Diseases (515)

Medicine General Internal (349)

Immunology (349)

Microbiology (328)

Mycology (229)

We can observe that the category Infectious Diseases is the most dominant Science Category. In order to understand better the distribution of Science Categories of CM-research, we may look at the distribution of Source Titles:

Table 3. The distribution of Source Titles of the CM-research

Clinical Infectious Diseases (105)

Infection and Immunity (56)

American Review of Respiratory Disease (50)

Mycopathologia (42)

Chest (41)

A journal for "clinical infectious diseases" has published most of the CM-articles. 
There is an overlapping between Table 2 and Table 3:

Namely, the terms "infectious diseases" and "mycology" are common in both Tables.

\title{
2.3 The Significant Authors, Editors and Organizations
}

Our database can provide information to estimate the most prolific authors and the most citated authors of the CM-research.

The most prolific authors are in order in Table 4:

Table 4. Prolific Authors in Terms of Publications

Pappagianis D (94)

Galgiani JN (89)

Stevens DA (84)

Ampel NM (77)

Blair JE (63)

Charles Smith's epigone Demosthenes Pappagianis has been studied at Stanford and Berkeley and now works at UC-Davis. He is one of the oldest and the most productive CM-researchers in the world (90+ years old).

John Galgiani works at the University of Arizona.

Editors are also important in the scientific diffusion of the CM-research. In Table 5 the most important editors are evaluated:

Table 5. Editors
Einstein HE (39)
Clemons KV (37)
Stevens DA (36)
Laniado-Laborin R (36)

It seems that the four most important editors have almost equal production.

The next Table 6 depicts the organizations with the number of publications.

Table 6. Organizations

\author{
University of California System (369) \\ University of Arizona (244) \\ University of California-Davis (138) \\ Mayo Clinic (106) \\ Stanford University (100)
}

The two CM-infected states in the US are also the most productive in research: California and Arizona. Stanford and UC-Berkeley have a historical value-added of research per se within the California state. Davis was once the agricultural college of Berkeley. However, when Davis became independent of Berkeley, a group of CM-scholars (Pappagianis and others) moved from Berkeley to Davis with their laboratory. This is the explanation of the high productivity of UC-Davis. The citation is an index of research impact. The most cited authors of the CM-research are written in Table 7. 
Table 7. Citations

Wallis RS et al. (2004) .................................531

McNeil MM et al. (1998)

Galgiani JN et al. (2005) 287

Zwirewich, CV et al. (1991) ..............................261

Drutz DJ (1978)

The first two articles are Conference Articles, and the other articles are Journal Articles. The citation is an index of the research impact. Galgiani is one of the most prolific and cited authors. He might verify the "Matthew effect" in the CM-research (Merton, 1968):

"A macroscopical version of the Matthew principle is apparently involved in those processes of social selection that currently lead to the concentration of scientific resources and talent. "

\subsection{The Financing of CM-Research}

Finally, the financing of CM-research is a vital and complex question which affects the entire subject area. There are major differences between regions: North America vs. Latin America, America vs. Europe, Germany vs. other EU-states, etc.

The medical control system of a country to produce a new medicine is extremely important too. The form of longitudinal studies (number of patients and the number of years) can increase the costs of the new medicine.

Yet, research shows that a vaccine is, indeed, possible (Cole, et al., 2004; Galgiani, 2008) and perhaps a change in the conventional business model for vaccine development should be modified, as Galgiani suggests.

"The industry had been slow to invest, with prior outbreaks limited in scale and a virus believed confined within poor countries."

We may expect that the Funding Agencies based in the US will be the dominant agencies in the international market.

Table 8. Funding Agencies

NIAID NIH HHS (84)

Pfizer (16)

NIH (9)

Astellas (9)

Merck (8)

The National Institutes of Health (NIH) finance more CM-projects than the private companies. There is no available information in our sample for the money value of these projects.

It may take an international partnership between industry and governments to solve or significantly reduce the problem of CM, mutually investing in risk avoidance measures, to "promote the general welfare," a purpose of government, as the preamble to the U.S. Constitution states. Long-term views are needed, a higher quality of government, as important questions arise because the cocci fungus is so linked to the variability of weather and future climates - and to how society responds (Sarafoglou et al., 2016). Will deserts and the range of CM expand or "migrate" to unsuspecting populations? Employment in solar energy fields has become a new, high-risk occupation for CM in this growing industry will new "migrant" workers from non-endemic areas be especially vulnerable?

Recently, Deresinski and Mirels, (2019) wrote:

"The search for the "Holy Grail" - a vaccine capable of preventing this disease-continues".

\section{Epilogue}

The CM-research is a multidisciplinary research. Geology, Atmospheric Sciences, Medicine and Public Health are the main disciplines. The higher interaction of these disciplines could generate a more effective CM-treatment. In other words, the complexity of the CM-research needs a holistic (transdisciplinary) approach. 
Another older philosophical explanation of CM-research interpretation with respect to publications and citations by scholars might be similar to Plato's "Allegory of the Cave" in his "Republic." According to this allegory, prisoners isolated in a cave with limited lighting could see the shadows of the objects and tried to identify them (Baggott, 2011). This allegory symbolizes the constraints of human knowledge in relation to the actual reality.

\section{Acknowledgements}

We are obliged to Demosthenes Pappagianis, Bill Sprigg, and Patrick Quinn for their comments.

\section{Notes:}

/1/ The year 2017 has been calculated for the first 6 months of this year.

\section{References}

Ajello, L. (1967). Comparative ecology of respiratory mycotic disease agents. Bacteriol Rev., 31, 6-24.

Ampel, N. M. ( 2015). The treatment of Coccidioidomycosis. Rev. Inst. Med. Trop. Sao Paulo, 57(Suppl. 19), 51-56. https://doi.org/10.1590/S0036-46652015000700010

Arizona Department of Health Services (ADHS). (2007). Valley Fever Annual Report. Retrieved from http://azdhs.gov/phs/ oids/epi/disease/valley-fever/documents/reports/valley-fever-annual-report- 2007.pdf

Arizona Department of Health Services (ADHS). (2012). Arizona Valley Fever Report 2007-2011. Phoenix, AZ.

Baggott, J. E. (2011). The Quantum Story. Oxford Univ. Press.

Baptista, R. R. C., \& Riquelme, M. (2007). Epidemiologia de la coccidioidomicosisen Mexico. Rev Iberoam Micol., 24, 100-105. https://doi.org/10.1016/S1130-1406(07)70022-0

Bercovitch, R. S, Catanzaro, A., Schwartz, B. S., Pappagianis, D., Watts, D. H., \& Ampel, N. M. (2011). Coccidioidomycosis during pregnancy: a review and recommendations for management. Clin Infect Dis., 53(4), 363-368. https://doi.org/10.1093/cid/cir410

Bialek, B., Kern, J., Hermann, T., Tijerina, R., Ceceñas, L., \& Reischi, U. et al., (2004). PCR assays for identification of Coccidioides posadasii based on the nucleotide sequence of the antigen 2/proline-rich antigen. J Clin Microbiol., 42 , 778-783. https://doi.org/10.1128/JCM.42.2.778-783.2004

Blair, J. E. (2009). Coccidioidal meningitis: update on epidemiology, clinical features, diagnosis, and management. Curr Infect Dis Rep, 11(4), 289-295. https://doi.org/10.1007/s11908-009-0043-1

Castañeda-Godoy, R., \& Laniado-Laborin, R. (2002). Coexistencia de tuberculosis y coccidioidomicosis. Presentación de dos casos clínicos. Rev Inst Nal Enf Resp Mex, 15, 98-101.

Castañon-Olivares, L. R., Aroch-Calderon, A., Bazan-Mora, E., \& Cordova-Martınez, E. (2004). Coccidioidomicosis y su escaso conocimiento en nuestro país. Rev Facultad Med UNAM., 47, 4.

Castro, A., \& Trejos, A. (1951). Confirmation of the first Central American case of coccidiodomycosis. Rev Med Costa Rica., 10, 89-90.

Centers for Disease Control and Prevention (CDC), (1994). Coccidioidomycosis - California, 1991-1993. MMWR 43(23), 421-423.

Centers for Disease Control and Prevention (CDC). (2001). Coccidioidomycosis in Workers at an Archeologic Site Dinosaur National Monument, Utah, June-July 2001. Morbidity and Mortality Weekly Report (MMWR), 50(45), 1005-1008.

Cole, G. T. et al. (2004): A vaccine against coccidioidomycosis is justified and attainable; Med Mycol., 42(3), $189-216$. https://doi.org/10.1080/13693780410001687349

Cooksey, G. S., Nguyen, A., Knutson, K., Tabnak, F., Benedict, K., McCotter, O. Z. et al. (2017). Notes from the field: increase in Coccidioidomycosis-California, 2016. MMWR Morb Mortal Wkly Rep., 66, 833-834. https://doi.org/10.15585/mmwr.mm6631a4

de Aguiar Cordeiro, R., Patoilo, K. R., Praciano, S. B., Medrano, D. J., de Faris Marques, F. J., \& Martins, M. L. et al. (2013). Antigens of Coccidioides posadasii as an important tool for the immunodiagnosis of coccidioidomycosis. Mycopathologia, 175(1-2), 25-32. https://doi.org/10.1007/s11046-012-9604-1

de Solla Price, D. (1976). A general theory of bibliometric and other cumulative advantage processes. Journal of the American Society for Information Science, 27, 292-306. https://doi.org/10.1002/asi.4630270505

Deresinski, S., \& Mirels, L. F. (2019). Coccidioidomycosis: What a long strange trip it's been. Medical Mycology, 57, Issue Supplement 1. https://doi.org/10.1093/mmy/myy123 
Engelthaler, D. M., Roe, C. C., Hepp, C. M., Texeira, M., Driebe, E. M., \& Schupp, J. M. et al. (2016). Local population structure and patterns of Western Hemisphere dispersal for Coccidioides spp., the fungal cause of valley fever. $m$ Bio. 7, e00550-16. https://doi.org/10.1128/mBio.00550-16

Fiese, M. J. (1958). Coccidioidomycosis. C. C. Thomas Publishers.

Fisher, F. S., Bultman, M. W., Johnson, S. M., Pappagianis, D., \& Zaborsky, E. (2007). Coccidioides niches and habitat parameters in the southwestern United States: a matter of scale. Ann $N$ Y Acad Sci., 1111, 47-72. https://doi.org/10.1196/annals.1406.031

Forsbach-Sanchez, G. B., \& Fuentes-Pensamiento, R. (1985). Coccidioidomicosis pulmonar cronica progresiva en una paciente con diabetes mellitus II. Rev Inv Clin., 37, 49-51.

Freedman, M., Jackson, B. R., McCotter, O., \& Benedict, K. (2018). Coccidioidomycosis outbreaks, United States and Worldwide, 1940 -2015. Emerg Infect Dis., 24(3), 417-423. https://doi.org/10.3201/eid2403.170623

Galgiani, J. N. (2008). Vaccines to Prevent Systemic Mycoses: Holy Grails Meet Translational Realities; J. Infectious Diseases, 197, 938-940. https://doi.org/10.1086/529205

Galgiani, J. N. et al. (2005). Coccidioidomycosis.Clin. Infect. Dis., 41, 1217-1223. https://doi.org/10.1086/496991

Galgiani, J. N., Ampel, N M., Blair, J. E., Catanzaro, A., Geertsma, F., \& Hoover, S. E. et al. (2016). Infectious Diseases Society of America (IDSA) Clinical Practice Guideline for the Treatment of Coccidioidomycosis. Clin Inf Dis., Sep 15; 63(6), e112-46. https://doi.org/10.1093/cid/ciw538

Galgiani, J. N., Catanzaro, A., Cloud, G. A., Johnson, R. H., Williams, P. L., \& Mirels, L. F. et al. (2000). Mycoses Study Group. Comparison of oral fluconazole and itraconazole for progressive, nonmeningeal coccidioidomycosis. A randomized, double-blind trial. Ann Intern Med., 133(9), 676-686. https://doi.org/10.7326/0003-4819-133-9-200011070-00009

Garcia, V. A., Close de, L. J., \& Rivera, L J. (1960). Coccidioidomycosis comunication of the first human case in Guatemala. Revista del Colegio Medico de Guatemala., XI, 284-289.

Gia, G. P. (2014). Dust Storms and Valley Fever 1874-2014. Retrived from www.gillbertgia.com

Hector, R. F. et al. (2011). Public health impact of coccidioidomycosis in California and Arizona. International Journal Environ. Res. Publ. Health, 8, 1150-1173. https://doi.org/10.3390/ijerph8041150

Hector, R. F., \& Laniado-Laborin, R. (2005). Coccidioidomycosis-A fungal disease of the Americas. PLoS Med, 2(1), e2. https://doi.org/10.1371/journal.pmed.0020002

Hirschmann, J. V. (2007). The early history of Coccidioidomycosis: 1892-1945. Clin Infect Dis., 44(9), 1202-1207. https://doi.org/10.1086/513202

Hospenthal, D. R. (2013): Coccidioidomycosis. Emedicine.medscape.com/article/215978-overview.

Huang, J. Y. (2012). Coccidioidomycosis-associated Deaths, United States, 1990-2008. Emerg. Infect. Dis., 18(11), 1723-1728. https://doi.org/10.3201/eid1811.120752

IPCC. (2007). Climate Change 2007: Synthesis Report. Contribution of Working Groups I, II and III to the Fourth Assessment Report of the Intergovernmental Panel on Climate Change. IPPCC, Geneva.

Johnson, R. H., \& Einstein, H. E. (2006). Coccidioidal meningitis. Clin Infect Dis, 42(1), 103-107. https://doi.org/10.1086/497596

Kollath, D. R., Miller, K. J., \& Barker, B. M. (2019). The mysterious desert dwellers: Coccidioides immitis and Coccidioides posadasii, causative fungal agents of coccidioidomycosis, Virulence, 10(1), 222-233. https://doi.org/10.1080/21505594.2019.1589363

Laniado-Laborin, R. (2006). Coccidioidomicosis: mas que una enfermedad regional. Rev Inst Nal Enf Resp Mex, 19(4), 301-308.

Laniado-Laborin, R., Arathoon, E. G., Canteros, C., Muniz-Salazar, R., \& Rendon, A. (2019). Coccidioidomycosis in Latin America. Medical Mycology, 57, S46-S55. https://doi.org/10.1093/mmy/myy037

Laniado-Lavorin, R. (2007). Expanding understanding of epidemiology of Coccidioidomycosis in the Western hemisphere. Annals, N.Y. Academy of Science, 1111, 19-34. https://doi.org/10.1196/annals.1406.004

McCotter, O. Z., Benedict, K., Engelthaler, D M., Komatsu, K., Lucas, K. D., \& Mohle-Boetani, J. C. et al. (2019). Update on the Epidemiology of coccidioidomycosis in the United States. Medical Mycology, 57, S30-S40. https://doi.org/10.1093/mmy/myy095

Merton, R. K. (1968). The Matthew Effect in Science. Science, 159, 56-63. https://doi.org/10.1126/science.159.3810.56 
Odio, C. D., Marciano, B. E., Galgiani, J. N., \& Holland, S. M. (2017). Risk factorsfor disseminated coccidioidomycosis, United States. Emerg Infect Dis., 23(2). PubMed PMID: 28098554. https://doi.org/10.3201/eid2302.160505

Pappagianis, D. (1994). Marked increase in cases of coccidioidomycosis in California: 1991, 1992, and 1993. Clin Infect Dis., 19, S14-S18. https://doi.org/10.1093/clinids/19.Supplement_1.14

Pappagianis, D. (2001). Seeking a vaccine against Coccidioides immitis and serologic studies: expectations and realities. Fungal Genet Biol, 2001, 32(1), 1-9. https://doi.org/10.1006/fgbi.2000.1243

Pappagianis, D., \& Einstein, H. (1978). Tempest from Tehachapi takes toll or Coccidioides conveyed aloft and afar. West. J. Med., 129, 527-530.

Parish, J. M., Blair, J. E. (2008). Coccidioidomycosis. Mayo Clin Proc 2008, 83(3), 343-348. https://doi.org/10.4065/83.3.343

Perez-Guisasola, E., \& Rosal, J. E. (1960). Human cocciodioidomycosis in Guatemala mycologic, histopatholocic diagnosis and biologic confirmation of the first case. Revista del Colegio Medico de Guatemala., XI, 290-294.

Plato (2012). Republic. Penguin.

Rixford, E., \& Gilchrist, T. C. (1896). Two cases of protozoan (coccidioidal) infections of the skin and other organs. $J$. Hopkins Hosp. Rep., 1, 209-268.

Sandelin, B., \& Sarafoglou, N. (2004). Language and scientific publication statistics. Language Problems and Language Planning, 28(1), 1-10. https://doi.org/10.1075/lplp.28.1.02san

Sarafoglou, N., \& Kafatos, M. (2013). Infrastructure vulnerability and climate, in R. Pielke (ed): Climate Vulnerability, Elsevier, Amsterdam.

Sarafoglou, N., Kafatos, M., \& Beall, J. H. (2012). Simultaneity in Scientific Enterprise. Studies in Sociology of Science, $3(3), 20-30$.

Sarafoglou, N., Kafatos, M., \& Sprigg, W. A. (2016). Migration, environment and public health: Theory and interdisciplinary research from a regional science perspective. Int'l J. Soc. Sci. Stud., 4(4), 122-135. https://doi.org/10.11114/ijsss.v4i4.1473

Smith, C. E. (1940). Epidemiology of acute coccidioidomycosis with erythema nodosum ("San Joaquin" or "Valley fever"). Am. J. Pub. Health, 30, 600-611. https://doi.org/10.2105/AJPH.30.6.600

Sondermeyer, G. et al., (2013). Coccidioidomycosis-associated hospitalizations, California, USA, 2000-2011. Emerg infect Dis., 19, 1590-1598. https://doi.org/10.3201/eid1910.130427

Sprigg, W. A. (2008). Public health applications in remote sensing. https://doi.org/10.1117/2.1200902.1488

Sprigg, W. A. et al. (2012). Airborne Dust Models: A Tool in Environmental Health Tracking. Center for Disease Control and Prevention, CDC, Atlanta, GA.

Sprigg, W. A. et al., (2014). Regional dust storm modeling for health services: The case of valley fever. Aeolian Research (forthcoming). https://doi.org/10.1016/j.aeolia.2014.03.001

Sunenshine, R. H., Anderson, S., Erhart, L., Vossbrink, A., Kelly, P. C., \& Engelthaler, D. et al. (2007). Public health surveillance for coccidioidomycosis in Arizona. Ann N Y Acad Sci, 1111, 96-102. https://doi.org/10.1196/annals.1406.045

Tamerius, J. D., \& Comrie, A. C. (2011). Coccidioidomycosis incidence in Arizona predicted by seasonal precipitation. PloS one, 6(6), e21009. https://doi.org/10.1371/journal.pone.0021009

Thompson, III G. R., Lewis, II J. S., Nix, D. E., \& Patterson, T. F. (2019). Current Concepts and Future Directions in the Pharmacology and Treatment of Coccidioidomycosis. Medical Mycology, 57, S76-S84. https://doi.org/10.1093/mmy/myy029

Twarog, M., \& Thompson, III G. R. (2015). Coccidioidomycosis: Recent Updates. Semin Respir Crit Care Med., 36, 746-755. https://doi.org/10.1055/s-0035-1562900

Zuckerman, H. (1987). Citation analysis and the complex problem of intellectual influence. Scientometrics, 12, 329-338. https://doi.org/10.1007/BF02016675

\section{Copyrights}

Copyright for this article is retained by the author(s), with first publication rights granted to the journal.

This is an open-access article distributed under the terms and conditions of the Creative Commons Attribution license which permits unrestricted use, distribution, and reproduction in any medium, provided the original work is properly cited. 